\title{
Cytogenetic contribution to uniparental disomy (UPD)
}

Thomas Liehr

\begin{abstract}
Uniparental disomy (UPD) is often considered as an event to be characterized exclusively by molecular genetic or epigenetic approaches. This review shows that at least one third of UPD cases emerge in connection with or due to a chromosomal rearrangement. Thus, additional (molecular) cytogenetic characterization of UPD cases is essential. Up to now > 1,100 UPD cases detected in clinical, non-tumor cases are reported in the literature. Recently, these cases were summarized in a regularly updated, freely available online database http://www.med.uni-jena.de/ fish/sSMC/OOSTART-UPD.htm. Based of this, here the presently known imprinting syndromes, the chromosomal contribution to UPD phenomenon, and the cytogenetic subgroups of UPD, including cases with normal, abnormal balanced or unbalanced karyotype (like e.g. small supernumerary marker chromosomes and Robertsonian translocations) and segmental UPD are reviewed. Furthermore, chromosome fragmentation as a possible mechanism of trisomic rescue is discussed, which might help to explain the observed 1:9 rate of maternal versus paternal UPD present in cases with original trisomic karyotypes. Overall, as UPD is more but an interesting rarity, the genetic background of each "UPD-patient" needs to be characterized besides by molecular methods, also by molecular cytogenetics in detail.
\end{abstract}

\section{Introduction}

Uniparental disomy (UPD) is the presence of a chromosome pair derived only from one parent present in a disomic cell line [1]. When one of the first proven UPD case was published [2] an editorial in the same journal issue commented this by the words: < it seems unlikely that UPD will turn out to be anything but an interesting rarity $>$ [3]. However, today, some 20 years later, there are $>1,100$ reports on UPD cases [1] and what was considered initially as something exotic is nowadays an important diagnostic [4] and even prognostic factor for special syndromes $[5,6]$. Also UPD is able to support the localization of monogenic disorder genes (e.g. [7], see also [1]) and was demonstrated to play a role in tumorigenesis, as reviewed by [8].

The concept of UPD was introduced in 1980 into medical genetics by Eric Engel [9]. In 1987 the first case of UPD proven by molecular methods was described [10]. However, cases having a UPD were reported before [11-14].

Correspondence: i8lith@mti.uni-jena.de

Jena University Hospital, Institute of Human Genetics and Anthropology, Kollegiengasse 10, D-07743 Jena, Germany
In theory there are 48 possible uniparental chromosomal pairs, plus 2 whole genomic variants of UPD which could exist. Up to present no maternal UPD was reported for chromosome 19 (and Y), and no paternal UPD for chromosomes 4, 17, 18 and 19 [1]. UPD can be detected based on cytogenetic data and chromosomal heteromorphisms or rearrangements [10-14], microsatellite analysis [15], methylation test [16] or SNP-bases array-comparative genomic hybridization [15]. Also molecular cytogenetics taking advantage of the so called copy number variations (CNV) within the human genome can be used to characterize UPD [17]. Interestingly, UPD is in at least $30 \%$ of the case observed together with a chromosomal aberration [1]. Thus, (molecular) cytogenetics is essential when concentrating on this putatively exclusive molecular genetic topic.

This review focuses on UPD present in clinically normal and clinically abnormal persons. UPD cases nowadays repeatedly reported as acquired, tumor-specific epigenetic alteration [8] are not subject of this paper. Basis of this review is a freely available and regularly updated online database including all published UPDcases [1]. 


\section{Basic types of UPD}

According to [18] there are three basis types of UPD. UPD for the entire chromosomal complement can be present as paternal or maternal UPD (UPDpat/ UPDmat). The first leads to complete hydatidiform mole, the second one induces benign cystic ovary. For UPDpat exceptional cases are reported with mosaic state of uniparental and biparental inheritance but no triploidy; more frequently UPDpat cell lines with a triploid one are seen as partial hydatidiform mole $[1,18]$.

UPD for a complete chromosome can appear due to gamete complementation, trisomic rescue (with or without formation of a small supernumerary marker chromosome $=\mathrm{sSMC}$ ), monosomic rescue, mitotic error in connection with a Robertsonian or other translocation, isochromosome formation, deletion and duplication [18]. Finally, segmental UPD can arise due to a postzygotic somatic recombination between maternal and paternal homologue, or in connection with numerical and/or structural chromosomal aberrations [18].

\section{Hetero- and isodisomy, imprinting and hemizygosity}

Two subtypes of UPD can be recognized by molecular analysis. The one is called heterodisomy (hUPD) and is defined as inheritance of both chromosomes from one parental pair. Besides there can be isodisomy (iUPD), i.e. inheritance of two copies of the same chromosomes from one parent. hUPD and iUPD can cause disease if affecting a gene underlying genomic imprinting (= expression of a gene which depends on parental origin). iUPD can further and independent of imprinting, result in functional reduction to hemizygosity and thus can cause a recessive disease to occur in the offspring of one carrier patient. Apart from monosomic rescue cases, which should always be iUPD, hUPD and iUPD can be observed as mixed forms mostly. Overall, mainly meiotic I or II errors and/or postzygotic events contribute to UPD formation [18]. Additionally, as Albert Schinzel stated $<$ the incidence of meiotic nondisjunction increases with advanced maternal age, maternal UPD most often is heterodisomy while in paternal UPD isodisomy prevails, and no correlation with paternal age is found $>$ [19].

As "imprinting disorders" are nowadays regarded and registered in the database Online Mendelian Inheritance of Man (OMIM) [20]:

- patUPD(6): transient neonatal diabetes (TND; OMIM \#601410),

- matUPD(7): Silver Russel syndrome (SRS; OMIM \#180860),

- patUPD(11): Beckwith-Wiedemann syndrome (BWS; OMIM \#130650),
- matUPD(14): Temple syndrome (TS; see OMIM *605636 and \#176270),

- patUPD(14): paternal UPD(14) syndrome (patUPD (14); OMIM \#608149),

- matUPD(15): Prader Willi syndrome (PWS; OMIM $\# 176270)$, and

- patUPD(15): Angelman syndrome (AS; OMIM $\# 105830)$.

Meiotic and mitotic origin of the UPD has been shown to be assorted in different imprinting disorders. Meiotic origin is e.g. suggested in $58 \%$ of matUPD(7)-, in $89 \%$ of matUPD(15)- and in $16 \%$ in patUPD(15)cases [21].

\section{Frequency of UPD}

According to the literature the frequency of UPD in newborn is considered to be about 1 in 3,500 which equals a rate of $0.029 \%$ [21]. However, the rate for a similar rare human group of disorders, in which UPD also can be present, i.e. the patients with small supernumerary marker chromosomes (sSMC), is only $0.044 \%$ in newborn [22]. At present almost 4,000 sSMC cases [23] and only $\sim 1,100$ UPD [1] cases are reported in the literature. Thus, the rate of UPD in human population might be even lower than suggested, maybe 1 in 5,000 or less.

However, in the above mentioned "imprinting disorders" the UPD rates are much higher. In SRS about 5\% of the cases show a matUPD(7). For AS a UPD rate of $7 \%$ [24] and for PWS of $25 \%$ is given [24,25]. BWS has segmental UPD(11p) in $20 \%$ of the cases. In TND a patUPD(6) is reported in $40 \%$ of the patients. > 95\% of TS cases show matUPD(14) and for patUPD(14) syndrome no cases without UPD are reported yet [24]. Also important to state is that UPD seems not to be promoted by assisted reproductive technologies (ART), while imprinting defects are very well found more frequently after application of ART [24].

As summarized in Table 1 the male to female ratio of UPD carriers overall is $1: 1$. Only for matUPD(4) and patUPD(6) this ratio was abnormal (Tab. 1). For matUPD(4) at present eight cases are reported, seven of which are male. In patUPD(6) only seven of the nineteen cases are female. Further cases have to be studied to be able to draw a final conclusion if these data are subject to bias or not.

\section{Detection of UPD}

In one third of clinical UPD cases this genetic defect is uncovered due to, or in connection with a chromosomal abnormality [1]. In such cases cytogenetic analysis was performed because in the overwhelming majority of the 
Table 1 Male to female ratio in maternal and paternal UPD for human autosomes.

\begin{tabular}{lrrrr}
\hline & matUPD & & patUPD & \\
\cline { 2 - 5 } Chromosome & Male & female & male & female \\
\hline 1 & 6 & 5 & 6 & 9 \\
\hline 3 & 9 & 7 & 6 & 4 \\
\hline 4 & 1 & 4 & 0 & 0 \\
\hline 5 & 7 & 1 & 0 & 0 \\
\hline 6 & 0 & 1 & 1 & 1 \\
\hline 7 & 3 & 3 & 12 & 7 \\
\hline 8 & 17 & 20 & 6 & 3 \\
\hline 9 & 2 & 3 & 1 & 1 \\
\hline 10 & 4 & 8 & 0 & 0 \\
\hline 11 & 3 & 1 & 0 & 0 \\
\hline 12 & 2 & 1 & 7 & 8 \\
\hline 13 & 1 & 3 & 0 & 1 \\
\hline 14 & 2 & 3 & 3 & 3 \\
\hline 15 & 20 & 24 & 12 & 15 \\
\hline 16 & 36 & 25 & 23 & 23 \\
\hline 17 & 13 & 13 & 0 & 2 \\
\hline 18 & 1 & 2 & 0 & 0 \\
\hline 19 & 0 & 1 & 0 & 0 \\
\hline 20 & 0 & 0 & 0 & 0 \\
\hline 21 & 3 & 2 & 1 & 0 \\
\hline 22 & 3 & 1 & 1 & 3 \\
\hline Overall & 136 & 133 & 2 & 1 \\
\hline As & 5 & 81 & 81 \\
\hline
\end{tabular}

As not for all reported UPD cases the gender is given in the literature only 413 cases summarized in [1] could be included in this table.

cases with a UPD clinical abnormalities are present. Only some 50 cases with UPD but no clinical abnormalities are reported in the literature; they were found more or less by chance or due to repeated abortions in a family with chromosomal rearrangement [1].

As the karyotype is crucial for the understanding of UPD formation, in the following the reported UPDcases are grouped into: 1) Cases with proven or suggested normal karyotype; 2) cases with abnormal balanced karyotype; 3) cases with abnormal unbalanced karyotype, subdividing in a) cases with small supernumerary marker chromosomes (sSMC) and b) cases with imbalances except for sSMC; and 4) cases with segmental UPD. The percentage rates given below are summarized in Fig. 1 and deduced from [1].

\section{Cytogenetic subgroups displaying UPD}

1) UPD-cases with proven or suggested normal karyotype $65 \%$ of the reported UPD cases have a cytogenetically proven or suggested normal karyotype of $46, \mathrm{XX}$ or 46 , XY (Fig. 1). Surprisingly, $>50 \%$ of these cases are published without having cytogenetics done. This is especially critical in UPD of one of the chromosomes $13,14,15,21$ or 22 (acrocentric ones). Presence of a Robertsonian translocation is known to contribute to the formation of this rare kind of mitotic error and can assist to explain familial cases of e.g. PWS or AS [26]. Between $0.6 \%$ and $3 \%$ of Robertsonian translocations are associated with UPD [27]. However, over $10 \%$ of the acrocentric chromosome derived UPDs summarized in [1] have a Robertsonian translocation.

\section{2) UPD-cases with abnormal balanced karyotype}

Abnormal balanced karyotypes in connection with UPD can be formed as isochromosomes (as described for chromosomes 1, 2, 4, 7 and 9), inversions (reported for chromosomes 3 and 4), balanced translocations (see chromosomes 7, 15) and Robertsonian translocations (chromosomes 13, 14, 15, 21 and 22). Overall, such abnormal balanced karyotypes are reported in $8 \%$ of published UPD cases [1] (Fig. 1).

\section{3) UPD-cases with abnormal unbalanced karyotype}

$16 \%$ of reported UPD cases are observed in connection with an unbalanced karyotype. About a quarter of those cases were identified due to the presence of an sSMC [1,23] (Fig. 1).

\section{3a) UPD-cases with SSMC}

All reported sSMC cases are summarized at http://www. med.uni-jena.de/fish/sSMC/00START.htm[23]. At present there are $>3,900$ entries with sSMC; 3,300 of those are reported not in connection with a Turner syndrome. Thus, at least $1.3 \%$ of those sSMC cases present with a UPD. This rate would be higher if derivativechromosome-22-/Emanuel-syndrome would be included; however, to the best of our knowledge no reliable quantitative data on parental UPD(22) origin is available here. Among the reported UPD cases SSMC were present in $4 \%$. As up to present only de novo sSMC were associated with a UPD, trisomic rescue is the most likely reason for their formation. This assumption was also already proven for some UPD cases (e.g. [28]).

\section{3b) UPD-cases with imbalances except for $S S M C$}

Trisomic rescue can not only lead to sSMC formation but also, more often, to mosaic formation like mos 47, $\mathrm{XN},+16 / 46, \mathrm{XN}$; in such cases a UPD, in the given example a UPD 16, can be present in the cells with normal karyotype. Over 100 such cases are reported, at present for chromosomes 2, 4, 6-7, 9-17 and 20-22. Besides, imbalances like additional sex chromosomes, pseudodicentric chromosomes, unbalanced translocations, partial deletions and duplications are reported in the remainder $\sim 25$ cases. In UPD-cases with additional imbalances it is hard to distinguish between a possible effect of UPD and of the observed chromosomal 

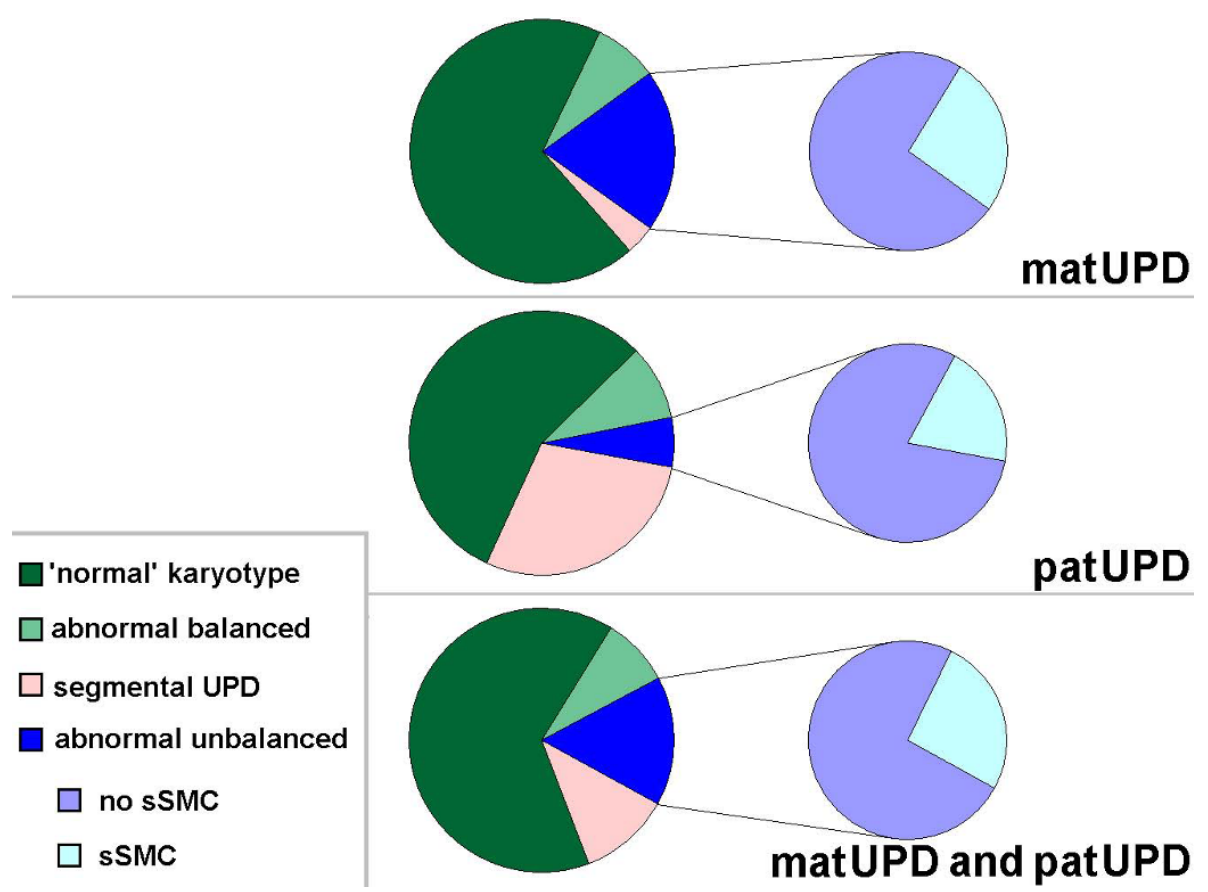

Figure 1 Cytogenetic subgroups displaying matUPD, patUPD and UPD in general. Abbreviations: matUPD = maternal UPD; patUPD = paternal UPD.

imbalance on the clinical phenotype. Also, if no chromosomal imbalance has been detected except for UPD, there still can be aberrant cell lines present in other than the studied body tissues. This topic is matter of discussion especially for matUPD(16) [29]. Additionally, it is noteworthy that in the here discussed mosaic cases with a trisomic cell line the disomic cells have a UPD and the trisomic ones not. However, there are mosaic cases with UPD reported especially for cases with BWS, but also other chromosomes [1]. Mostly these can be acknowledged only by molecular approaches, as cytogenetically the different cell lines do not differ.

\section{4) Segmental UPD-cases}

At present there are 122 reports on segmental UPD. $\sim 65 \%$ of those cases are provided by Beckwith-Widemann syndrome and segmental paternal UPD 11p [1]. The remainder cases were found in connection with chromosomal rearrangements in $\sim 12 \%$, while a normal or no karyotype is reported in 20 and 16 cases, respectively. Overall, $11 \%$ of all known UPD cases are of the segmental type (Fig. 1).

\section{Chromosomal contribution to UPD in autosomal chromosomes}

In Fig. 2 the chromosomal contribution to UPD together with matUPD and patUPD is summarized. Chromosomes 15, 11, 7, 14 and 16 are most often involved in UPD formation, chromosome 15 being by far the most often observed one, which might possibly reflect in parts an ascertainment bias. Chromosomes 1, 2 and 6 have a moderate frequency of UPD, while the remainder chromosomes are sparsely contributing to UPD.

Kalouseck and Barrett [30] suggested that the frequency with which various chromosomes are involved in placental aneuploidy could correspond to the incidence of specific chromosomal trisomies in spontaneous abortions. Thus, a data from a review on chromosomal contribution in spontaneous abortion [31] was compared with chromosomal contribution of UPD as known by now, excluding segmental UPD cases [1]. However, as visible in Fig. 3 there is no positive correlation, but, if at all a negative one. If true, this would possibly mean that chromosomes which tend to form UPD are found less frequently in abortions. Further studies are required to substantiate this possibility.

\section{Maternal and paternal UPD}

Trisomic rescue as reason for UPD is present in most of the SSMC- and of the mosaic-cases having trisomy in a subset of their cells. Overall, about 150 such cases are available in the literature. The fact that only 4 of 45 sSMC- and 9 of 107 mosaic-carriers show a paternal UPD, i.e. only $8.6 \%$, must have a biological background. It was already speculated that this might be due to the 


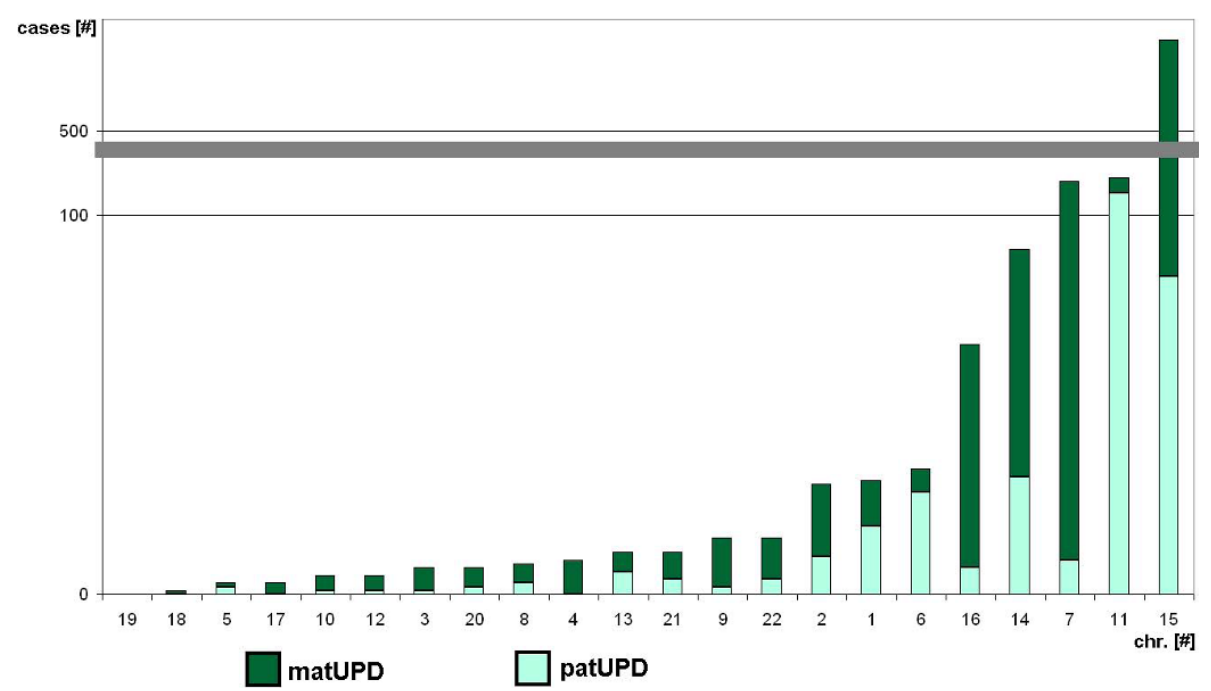

Figure 2 Chromosomal contribution to UPD. Maternal (matUPD) and paternal (patUPD) are presented in different colors. Abbreviations: \# = number; chr. = chromosome.

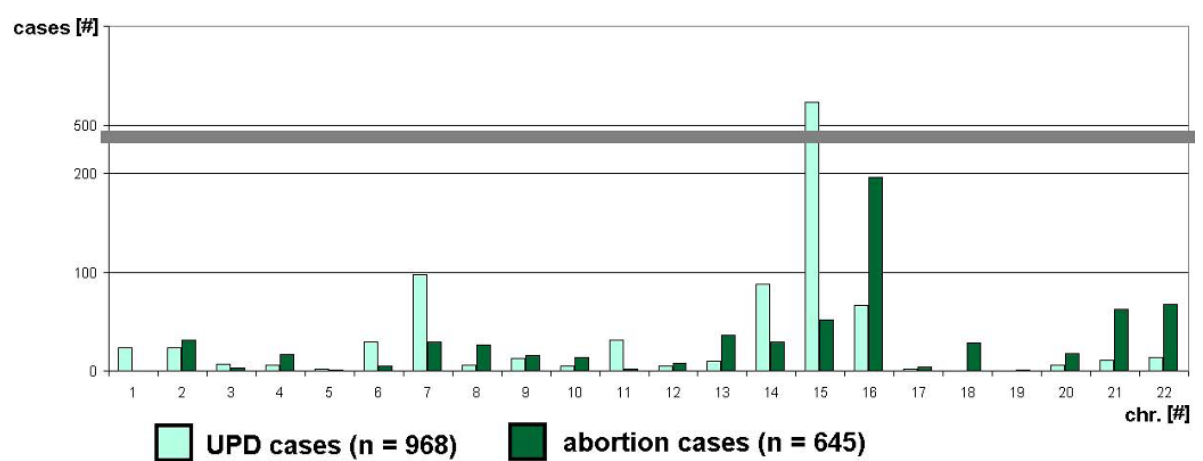

Figure 3 Chromosomal distribution of UPD compared to that found in abortions. Abbreviations: \# = number; chr. = chromosome; $\mathrm{n}=$ quantity of cases.

higher frequency of aneuploidy in oocytes than in sperm [32]. Chromosome anomalies are common in human gametes, with approximately $21 \%$ of oocytes and $9 \%$ in sperm [33]. In implanted embryos the rate of trisomies was estimated to be $16 \%$ [34]. Trisomic rescue is the result of viable postzygotic non-disjunction or anaphase lag event occurring during early embryogenesis which can involve either trophectoderm or extraembryonic mesoderm progenitors or both of them [35]. Los and coworkers added to that in 1998 the theory of chromosome demolition as an alternative correction mode [36]. As UPD and sSMC formation can go together, chromosome demolition would be a process of deliberate fragmentation and/or removal of one of the sets of three chromosomes during ana- or metaphase. Such chromosome fragmentation is seen in Howel Joly bodies [37] and a case with a del(5)(q31) recently reported could be interpreted as incomplete chromosome fragmentation
[38]. Also the recently recognized phenomenon that "developmental chromosome instability" is significantly increased during embryonic stage and affects different tissues is to be mentioned in this context [39]. Los and coworkers [36] < consider trisomic rescue to consist of one correction event in the first to fourth postzygotic cell division with a subsequent unknown distribution of trisomic and disomic cells among the progenitor cells of the inner cell mass and trophoblast compartment until 16-cell stage $>$. Cellular selection during following formation of placenta and early embryogenesis would help as a result to ensure the presence of a numerically balanced chromosome complement in the developing fetus.

Together with the recent findings that there are inherent epigenetic differences between the paternal and maternal pronuclei in early cleavage stage embryos [40] this led us to suggest the following idea to explain the 
above mentioned 1:9 rate of matUPD versus patUPD. Besides the fact that aneusomies are more likely to be contributed from the female side [32] also another kind of enzymatic content in male and female derived pronuclear compartment could be important. The oocyte has obviously a less active machinery to eliminate chromosomal mistakes than the spermatocyte. Thus, at stage of pronuclei an elimination of a paternally derived additional chromosome could be more likely than of a maternally derived one. In concordance herewith, evidence for the existence of a chromosome counting mechanisms in zygote and early embryogenesis was already provided [41].

\section{Conclusion}

Based on a regularly updated case collection on clinical UPD cases [1] meta-analyses of the presently available case-reports are now possible. Here a first attempt is presented. Similar as stated for the sSMC database [23] in [42] the present UPD-cases collected [1] are ascertainment-biased, however, it is the only data available by now. Of the 48 possible uniparental chromosomal pairs, plus 2 whole genomic variants of UPD still the first reports for mat UPD(19) and patUPD(4), patUPD(17), patUPD(18), and patUPD(19) are awaited. However, the rate of UPD might be lower than that of SSMC, and thus, lower than predicted [21]. Trisomic rescue and UPD should be highly actual fields of research, as the understanding of nuclear architecture and interphase cell regulation is nowadays considered as important for epigenetic gene regulation [43]. Thus, interphase cytogenetic tools like fluorescence in situ hybridization based banding approaches including multicolor banding could also be of interest in UPD-research [43-46].

What cannot be stressed enough is that the genetic background of a 'UPD-patient' needs to be characterized, besides by molecular methods, also by (molecular) cytogenetics as in one third of the cases chromosomal rearrangements are in connection with the event of a UPD!

\section{Authors' contributions}

TL contributed all work related to the UPD-database [1] and to this review.

\section{Competing interests}

The author declares that he has no competing interests.

Received: 23 March 2010 Accepted: 29 March 2010

Published: 29 March 2010

\section{References}

1. Liehr T: Cases with uniparental disomy (UPD). 2010 [http://www.med.unijena.de/fish/sSMC/OOSTART-UPD.htm].

2. Spence JE, Perciaccante RG, Greig GM, Willard HF, Ledbetter DH, Hejtmancik JF, Pollack MS, O'Brien WE, Beaudet AL: Uniparental disomy as a mechanism for human genetic disease. Am J Hum Genet 1988, 42:217-226.
3. Warburton D: Uniparental disomy: a rare consequence of the high rate of aneuploidy in human gametes. Am J Hum Genet 1988, 42:215-216.

4. Eggermann T, Meyer E, Ranke MB, Holder M, Spranger S, Zerres K, Wollmann HA: Diagnostic proceeding in Silver-Russell syndrome. Mol Diagn 2005, 9:205-209.

5. Halit H, Grice SJ, Bolton R, Johnson MH: Face and gaze processing in Prader-Willi syndrome. J Neuropsychol 2008, 2:65-77.

6. Weksberg R, Squire JA: Molecular biology of Beckwith-Wiedemann syndrome. Med Pediatr Oncol 1996, 27:462-469.

7. Woodage T, Prasad M, Dixon JW, Selby RE, Romain DR, ColumbanoGreen LM, Graham D, Rogan PK, Seip JR, Smith A: Bloom syndrome and maternal uniparental disomy for chromosome 15. Am J Hum Genet 1994, 55:74-80.

8. Tuna M, Knuutila S, Mills GB: Uniparental disomy in cancer. Trends $\mathrm{Mol}$ Med 2009, 15:120-128.

9. Engel E: A new genetic concept: uniparental disomy and its potential effect, isodisomy. Am J Med Genet 1980, 6:137-143.

10. Créau-Goldberg N, Gegonne A, Delabar J, Cochet C, Cabanis MO, Stehelin D, Turleau C, de Grouchy J: Maternal origin of a de novo balanced t(21q21q) identified by ets-2 polymorphism. Hum Genet 1987, 76:396-398.

11. Carpenter NJ, Say B, Barber ND: A homozygote for pericentric inversion of chromosome 4. J Med Genet 1982, 19:469-471.

12. Kirkels VG, Hustinx TW, Scheres JM: Habitual abortion and translocation (22q;22q): unexpected transmission from a mother to her phenotypically normal daughter. Clin Genet 1980, 18:456-461.

13. Palmer CG, Schwartz $S$, Hodes ME: Transmission of a balanced homologous $\mathrm{t}(22 \mathrm{q} ; 22 \mathrm{q})$ translocation from mother to normal daughter. Clin Genet 1980, 17:418-422

14. Betz A, Turleau C, de Grouchy J: Heterozygosity and homozygosity for a pericentric inversion of human chromosome 3. Ann Genet 1974, 17:79-80.

15. Altug-Teber O, Dufke A, Poths S, Mau-Holzmann UA, Bastepe M, Colleaux L, Cormier-Daire V, Eggermann T, Gillessen-Kaesbach G, Bonin M, Riess O: A rapid microarray based whole genome analysis for detection of uniparental disomy. Hum Mutat 2005, 26:153-159.

16. Baumer A, Wiedemann U, Hergersberg M, Schinzel A: A novel MSP/DHPLC method for the investigation of the methylation status of imprinted genes enables the molecular detection of low cell mosaicisms. Hum Mutat 2001, 17:423-430.

17. Mkrtchyan H, Gross M, Hinreiner S, Polytiko A, Manvelyan M, Mrasek K,

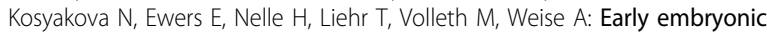
chromosome instability results in stable mosaic pattern in human tissues. Plos One 2010, 5:e9591.

18. Gardner RJM, Sutherland GR: Chromosome abnormalities and genetic counseling. Oxford University Press 2004, 314-318.

19. Schinzel $A$ : Catalogue of unbalanced chromosome aberrations in man. De Gruyter 2001, 19-22.

20. Online Mendelian Inheritance of Man (OMIM). 2010 [http://www.ncbi nlm.nih.gov/omim].

21. Robinson WP: Mechanisms leading to uniparental disomy and their clinical consequences. Bioessays 2000, 22:452-459.

22. Liehr T, Weise A: Frequency of small supernumerary marker chromosomes in prenatal, newborn, developmentally retarded and infertility diagnostics. Int J Mol Med 2007, 19:719-731.

23. Liehr T: Small supernumerary marker chromosomes (sSMC). 2010 [http://www.med.uni-jena.de/fish/sSMC/OOSTART.htm].

24. Amor DJ, Halliday J: A review of known imprinting syndromes and their association with assisted reproduction technologies. Hum Reprod 2008, 23:2826-2834.

25. Nicholls RD, Knoll JH, Butler, Karam S, Lalande M: Genetic imprinting suggested by maternal heterodisomy in nondeletion Prader-Willi syndrome. Nature 1989, 342:281-285.

26. Flori E, Biancalana V, Girard-Lemaire F, Favre R, Flori J, Doray B, Mandel JL: Difficulties of genetic counseling and prenatal diagnosis in a consanguineous couple segregating for the same translocation $(14 ; 15)$ $(q 11 ; q 13)$ and at risk for Prader-Willi and Angelman syndromes. Eur J Hum Genet 2004, 12:181-186.

27. Ruggeri A, Dulcetti F, Miozzo M, Grati FR, Grimi B, Bellato S, Natacci F, Maggi F, Simoni G: Prenatal search for UPD 14 and UPD 15 in 83 cases of familial and de novo heterologous Robertsonian translocations. Prenat Diagn 2004, 24:997-1000 
28. Bartels I, Schlueter G, Liehr T, Von Eggeling F, Starke H, Glaubitz R, Burfeind $P$ : Supernumerary small marker chromosome (SMC) and uniparental disomy 22 in a child with confined placental mosaicism of trisomy 22: Trisomy rescue due to marker chromosome formation. Cytogenet Genome Res 2003, 101:103-105.

29. Wolstenholme J: An audit of trisomy 16 in man. Prenat Diagn 1995, 15:109-121

30. Kalousek DK, Barrett I: Confined placental mosaicism and stillbirth. Pediatr Pathol 1994, 14:151-159.

31. Hassold T, Chen N, Funkhouser J, Jooss T, Manuel B, Matsuura J, Matsuyama A, Wilson C, Yamane JA, Jacobs PA: A cytogenetic study of 1000 spontaneous abortions. Ann Hum Genet 1980, 44:151-178.

32. Bán Z, Nagy B, Papp C, Beke A, Tóth-Pál E, Papp Z: Recurrent trisomy 21 and uniparental disomy 21 in a family. Fetal Diagn Ther 2003, 18:454-458.

33. Martin RH: Meiotic errors in human oogenesis and spermatogenesis. Reprod Biomed Online 2008, 16:523-531.

34. Farfalli VI, Magli MC, Ferraretti AP, Gianaroli L: Role of aneuploidy on embryo implantation. Gynecol Obstet Invest 2007, 64:161-165.

35. Kalousek DK, Howard-Peebles PN, Olson SB, Barrett IJ, Dorfmann A, Black SH, Schulman JD, Wilson RD: Confirmation of CVS mosaicism in term placentae and high frequency of intrauterine growth retardation association with confined placental mosaicism. Prenat Diagn 1991, 11:743-750.

36. Los FJ, van Opstal D, Berg van den C, Braat AP, Verhoef S, Wesby-van Swaay E, Ouweland van den AM, Halley DJ: Uniparental disomy with and without confined placental mosaicism: a model for trisomic zygote rescue. Prenat Diagn 1998, 18:659-668.

37. Felka T, Lemke J, Lemke C, Michel S, Liehr T, Claussen U: DNA degradation during maturation of erythrocytes - molecular cytogenetic characterization of Howell-Jolly bodies. Cytogenet Genome Res 2007, 119:2-8.

38. Vialard F, Molina-Gomes D, Quarello E, Leroy B, Ville Y, Selva J: Partial chromosome deletion: a new trisomy rescue mechanism? Fetal Diagn Ther 2009, 25:111-114.

39. lourov IY, Vorsanova SG, Yurov YB: Developmental neural chromosome instability as a possible cause of childhood brain cancers. Med Hypotheses 2009, 72:615-616.

40. Wu TF, Chu DS: Epigenetic processes implemented during spermatogenesis distinguish the paternal pronucleus in the embryo. Reprod Biomed Online 2008, 16:13-22.

41. Migeon BR, Jeppesen P, Torchia BS, Fu S, Dunn MA, Axelman J, Schmeckpeper BJ, Fantes J, Zori RT, Driscoll DJ: Lack of X inactivation associated with maternal $\mathrm{X}$ isodisomy: evidence for a counting mechanism prior to $X$ inactivation during human embryogenesis. Am J Hum Genet 1996, 58:161-170.

42. Liehr T, Mrasek K, Weise A, Dufke A, Rodríguez L, Martínez Guardia N, Sanchís A, Vermeesch JR, Ramel C, Polityko A, Haas OA, Anderson J, Claussen U, von Eggeling F, Starke H: Small supernumerary marker chromosomes-progress towards a genotype-phenotype correlation. Cytogenet Genome Res 2006, 112:23-34.

43. Manvelyan M, Kempf P, Weise A, Mrasek K, Heller A, Lier A, Höffken $K$, Fricke HJ, Sayer HG, Liehr T, Mkrtchyan H: Preferred co-localization of chromosome 8 and 21 in myeloid bone marrow cells detected by three dimensional molecular cytogenetics. Int J Mol Med 2009, 24:335-341.

44. Iourov IY, Liehr T, Vorsanova SG, Yurov YB: Interphase chromosomespecific multicolor banding (ICS-MCB): a new tool for analysis of interphase chromosomes in their integrity. Biomol Eng 2007, 24:415-417.

45. Manvelyan M, Hunstig F, Bhatt S, Mrasek K, Pellestor F, Weise A, Simonyan I, Aroutiounian R, Liehr T: Chromosome distribution in human sperm - a 3D multicolor banding-study. Mol Cytogenet 2008, 1:25.

46. Yurov YB, lourov IY, Vorsanova SG, Liehr T, Kolotii AD, Kutsev SI, Pellestor F, Beresheva AK, Demidova IA, Kravets VS, Monakhov W, Soloviev IV: Aneuploidy and confined chromosomal mosaicism in the developing human brain. PLoS One 2007, 2:e558.

doi:10.1186/1755-8166-3-8

Cite this article as: Liehr: Cytogenetic contribution to uniparental disomy (UPD). Molecular Cytogenetics 2010 3:8.

\section{Submit your next manuscript to BioMed Central and take full advantage of:}

- Convenient online submission

- Thorough peer review

- No space constraints or color figure charges

- Immediate publication on acceptance

- Inclusion in PubMed, CAS, Scopus and Google Scholar

- Research which is freely available for redistribution

Submit your manuscript at www.biomedcentral.com/submit 